\title{
La experiencia vivida de ser estudiante de bachillerato de nuevo ingreso
}

\section{The lived experience of being an incoming high school student}

Narciso Castillo Sanguino* | Gabriel Montes Sosa**

El artículo presenta parte de los resultados de una investigación más amplia cuyo objetivo es interpretar la experiencia escolar del estudiante de Bachillerato General Estatal en Puebla. El trabajo describe la experiencia vivida del estudiante de bachillerato de nuevo ingreso desde una perspectiva fenomenológica hermenéutica, mediante la cual se identifica que los estudiantes de nuevo ingreso enfrentan cambios y nuevas experiencias. La recolección de datos se realizó a partir de la aplicación de entrevistas fenomenológicas en profundidad y observación de cerca (centrada en la experiencia vivida); el análisis de datos fue de carácter temático. Los resultados muestran que existen cinco temas que estructuran la experiencia de llegar al bachillerato: vivir a la expectativa, falta de conexión, ganarse un lugar, entenderle al profesor y quiebre experiencial.

This paper introduce the lived experience of the newcomer high school student which is part of the results of a wider investigation which aims to interpret the Bachillerato General Estatal student's school experience in Puebla. From a Hermeneutic Phenomenology inquiry perspective, it was identified that the student's arrival is one of the most fundamental aspects of the high school student experience. The data were collected by in-depth phenomenological interviews and close observation and sent to thematic analysis. The results show that the high school students' arrival consists of five themes: To live with expectations, lack of connection, earning a place, understanding the teacher, and experiential break.

\author{
Palabras clave: \\ llegar al bachillerato, \\ experiencia vivida, \\ fenomenología \\ hermenéutica
}

\section{Keywords:}

high school arrival, lived experience, hermeneutic phenomenology

Recibido: 21 de enero de 2018. | Aceptado para su publicación: 11 de junio de 2018. Recuperado de: https://sinectica.iteso.mx/index.php/SINECTICA/article/view/834 DOI: 10.31391/S2007-7033(2018)0051-002

* Maestro en Calidad de la Educación por la UDLAP. Cursa el doctorado en Investigación e Innovación Educativa en la Benemérita Universidad Autónoma de Puebla. Sus líneas de investigación son la fenomenología y pedagogía, así como la adquisición de lenguas desde aproximaciones fenomenológicas. Correo: narciso.castillo@utim.edu.mx

** Doctor en Psicología por el Instituto Carl Rogers. Cursa estudios de doctorado en Filosofía Contemporánea en la Benemérita Universidad Autónoma de Puebla (BUAP). Profesor-investigadory colaborador del Colegio de Procesos Educativos, del Colegio de Filosofía y de la maestría en Educación Superior de la Facultad de Filosofía y Letras de la BUAP. Sus líneas de investigación son educación, psicología, estudios sobre afectividad desde aproximaciones fenomenológicas, historia de las ciencias sociales y psicoanálisis. Correo: laikatiti@hotmail.com. 


\section{INTRODUCCIÓN}

l abandono escolar es uno de los desafíos más importantes que enfrenta la

$\mathrm{E}$ educación media superior en México. De cada 100 niños que ingresan a la primaria, $73(73.4 \%)$ acceden al bachillerato y, de estos, solo 48 (47.7\%) logran terminarlo (Instituto Nacional para la Evaluación de la Educación [INEE], 2017). Si bien los jóvenes abandonan la escuela durante diferentes etapas del bachillerato, este fenómeno se acentúa con los que recién ingresan, según reporta el INEE, ya que de los jóvenes que abandonan sus estudios, $26.8 \%$ lo hacen durante el primer año, $10 \%$, en el segundo y $6 \%$, en el tercero.

En cierto modo, el primer año representa el gran filtro. Es claro que la deserción escolar se acrecienta más con los jóvenes de nuevo ingreso y va disminuyendo paulatinamente mientras avanzan en su trayectoria escolar. Así, resulta pertinente preguntarse ¿qué pasa con los jóvenes que se integran al bachillerato durante el primer año? ¿Cómo es su experiencia? ¿Qué retos enfrentan durante esta etapa?

El primer año de cada etapa escolar ha sido identificado como un estadio crucial en la trayectoria escolar de los jóvenes. En la literatura se habla del oficio de ser estudiante (Coulon, 1997), de college readiness (Hess, 2016) y de transición (Ganeson \& Ehrich, 2009). La primera propuesta entiende que ser estudiante es una actividad que debe ser aprendida del mismo modo que se aprende cualquier oficio. Así, el estudiante debe adquirir todas las habilidades y los conocimientos necesarios para desempeñar un buen papel en la escuela (Coulon, 1997; Weiss, 2012a, 2012b).

Por su parte, la propuesta college readiness identifica las variables necesarias para realizar estudios de manera exitosa en determinado grado escolar (Hess, 2016). Finalmente, los estudios de transición se centran en el análisis del periodo de cambio que experimentan los estudiantes de un nivel escolar a otro (Ganeson \& Ehrich, 2009; Tapia, 2015). Las tres aproximaciones convergen en el estudio del mismo fenómeno y en la persecución del mismo objetivo: hacer que los estudiantes accedan a un nuevo nivel educativo sin dificultad.

Los estudios centrados en este fenómeno lo han enfocado a partir de diversas categorías. Desde el sentido de pertenencia, desde el papel que juega la amistad, desde las consecuencias que una transición pobre tiene hacia el bienestar y el logro educativo. El hacer hincapié en estas categorías se da por las implicaciones del ser estudiante de nuevo ingreso, entre las que destaca el estrés que se genera por los cambios que los jóvenes encuentran en las nuevas materias, en los nuevos maestros, en los nuevos métodos instruccionales y en los nuevos compañeros (Rice, 2001).

El papel que juega la transición es trascendental. Los retos que enfrentan los recién llegados se concretan en la espera de un mayor aprendizaje autónomo que implica un menor acompañamiento por parte del docente. Además, los jóvenes experimentan cambios significativos en las relaciones con los compañeros: existe una mayor preocupación por ser aceptado socialmente, pérdida de autoestima que se cristaliza en un bajo rendimiento académico y aumento en los niveles de ansiedad y depresión (Hanewald, 2013; West, Sweetingm \& Young, 2010).

En el proceso de llegar a una nueva escuela es importante generar un sentido de pertenencia, el cual puede ser traducido como sentirse socialmente aceptado y apreciado por compañeros y maestros (Cueto, Guerrero, Sugimaru \& Zevallos, 2010; 
DeRobertis, 2017). Los mismos autores destacan que los jóvenes enfrentan una serie de desafíos a su llegada al bachillerato, entre ellos el aumento en la cantidad de profesores que les imparten clase, el incremento del trabajo escolar y el encuentro con compañeros provenientes de distintos contextos.

El papel de la amistad durante el periodo de transición escolar es un aspecto estudiado de suma importancia. El estrés y el sentimiento de no pertenencia es reducido sustancialmente por la creación de redes de conocidos, por los compañeros de grupos avanzados, por los propios compañeros y la ayuda del maestro (Ganeson \& Ehrich, 2009). Los estudiantes se apoyan en las relaciones con los demás, en especial encuentran en la amistad un soporte esencial para conectarse de manera rápida con la escuela (Weller, 2007). Al inicio los estudiantes buscan los rostros conocidos, ya sea los amigos que tuvieron en el nivel educativo anterior o el de los familiares.

Con lo anterior queda claro que la transición al bachillerato es de relevancia. Comprender la forma en la que los jóvenes se están incorporando al espacio escolar abona no solo a la comprensión de esta etapa, sino a obtener cierto conocimiento que puede servir de guía para una mejor transición. En México se ha dado un giro cuando se pregunta por los estudiantes de bachillerato, al pasar del quiénes al cómo son los estudiantes, con un creciente interés en la inclusión de sus voces (Guzmán y Saucedo, 2007; Saucedo, Guzmán, Sandoval y Galaz, 2013); asimismo, se ha discutido que ser estudiante de bachillerato es ser joven con todo el despliegue de la vida juvenil que esto implica (Weiss, 2012a); no obstante, la llegada al bachillerato es un aspecto de la experiencia escolar que ha sido poco tematizado.

\section{REFERENTES TEÓRICOS}

Este estudio se ancla en la fenomenología hermenéutica desarrollada por Heidegger, la cual se interesa por el mundo de la vida o la experiencia como es concretamente vivida (Laverty, 2003). Al referirnos al término experiencia vivida, hacemos alusión a un tipo de experiencia que nada tiene que ver con la acepción cercana a la experiencia acumulada ni a pruebas o a experimentos; se refiere más bien a nuestras vivencias, a eso que nos pasa (Larrosa, 2006, 2010). La experiencia vivida se deriva de la palabra alemana Erlebnis, que contiene la palabra Leben, que significa vida o vivir (Van Manen, 2014). De este modo, entendemos la experiencia de llegar al bachillerato como una experiencia vivida y que, en ese vivir, al joven que recién se incorpora al bachillerato "le pasan cosas" (Larrosa, 2006, 2010).

No puede haber experiencia vivida sin alguien a quien le acontezcan los momentos vividos. Heidegger (1997) entendió al ser humano como el ente que se pregunta por el Ser al que denominó Dasein, a menudo traducido como Ser-ahí o Ser-en-el-mundo. Este autor asevera que el Dasein no es un ente separado del mundo, sino que es producto de una formación histórica de la experiencia vivida (Laverty, 2003). El Dasein representa la comprensión elemental de lo que significa estar en el mundo, como un ser humano específico en una situación particular (Hodge, 2015). De este modo, podemos hablar del estudiante que recién se integra al bachillerato como un Dasein (una forma concreta del ser humano de estar en el mundo), cuyo mundo es representado por el bachillerato, entendiéndolo como el contexto significativo (Hodge, 2015) donde el joven que recién ingresa se encuentra con las situaciones, las cosas y la gente. 
En su estar en el mundo, el Dasein se encuentra con otros Dasein. Si bien es cierto que su estructura fundamental es su existencia, es importante hacer notar que el Dasein no existe si no coexiste; es un Mitsein, entendido como Ser-con otros (Heidegger, 1997). Así se pone de manifiesto la intersubjetividad, las relaciones que se establecen con el mundo y con los demás. Si entendemos al estudiante de recién ingreso al bachillerato como Dasein, el acontecer no es un acontecer en solitario, sino compartido con otros.

Para Heidegger (1997), el Dasein está arrojado en el mundo, condición que lo convierte en un ser no absoluto (no definido), abierto a distintas posibilidades, las cuales serán elegidas por él mismo. Partiendo de esta condición de arrojo, Martuccelli (2007) señala que en nuestra existencia estamos enfrentados a una serie de pruebas, entre las que destaca la prueba escolar. Para superar las pruebas, es necesario allegarse de soportes existenciales, entendidos como aquellos mecanismos que sostienen nuestra existencia. Un padre y una madre encuentran soporte en sus hijos, una persona solitaria puede hallar soporte en la amistad o en el trabajo. Martuccelli asevera que los soportes pueden ser afectivos, materiales, económicos, culturales y, en general, simbólicos; los entiende como aquellos motivos que nos hacen existir, que hacen nuestra existencia más pasajera o que le otorgan un sentido a nuestra vida.

\section{Metodología}

Nuestro estudio tiene un carácter fenomenológico hermenéutico (Van Manen, 2003, 2014) cuyo objetivo principal es regresar a los significados como son concretamente vividos (Finlay, 2009; Van Manen, 2014). La fenomenología hermenéutica se distingue por ser filosofía (teoría) y método; este último se caracteriza por estudiar la experiencia vivida junto a sus significados (Friesen, Henriksson \& Saevi, 2012). Como método de investigación, la fenomenología hermenéutica permite develar la forma en la que la experiencia de ser estudiante de bachillerato de nuevo ingreso se vive junto a sus significados, o si se prefiere, el significado de ser un estudiante de bachillerato de nuevo ingreso.

\section{Contexto}

La investigación se realizó con estudiantes de un bachillerato general estatal (BGE en lo subsecuente) localizado en el sur del estado de Puebla. El BGE es un subsistema de financiamiento estatal con presencia en todo el territorio poblano y se localiza mayormente en zonas rurales y semiurbanas. Este subsistema atiende $41 \%$ de la matrícula en esta entidad (SEP, 2016); si bien el BGE ha permitido ampliar la cobertura, no está exento de retos que debe superar, entre los que destacan elevar la calidad de maestros y directores, asegurar la terminación de sus estudiantes y diseñar sistemas de identificación temprana que permitan focalizar a los estudiantes en riesgo de abandono escolar (Organization for Cooperation and Development [OECD], 2013).

La ubicación del BGE contribuyó a masificar los servicios de bachillerato al atraer a estudiantes que son la primera generación dentro de sus familias en realizar este tipo de estudio. Con base en esta dinámica, los jóvenes que asisten al bachillerato Benito Juárez (lugar de la investigación) pueden ser tipificados como "nuevas figuras estudiantiles" (Guzmán, 2011). En lo académico, a diferencia de otras modalidades de 
bachillerato, el BGE no cuenta con un mecanismo de ingreso (OECD, 2013) (no aplica examen de admisión ni establece un promedio mínimo de ingreso). En promedio, la tasa de deserción del bachillerato Benito Juárez es de 15\%; de este porcentaje, la mayor parte de desertores cursaban el primer año. Desde este panorama, resulta interesante comprender la forma en la que los jóvenes se están incorporando al bachillerato.

\section{Muestra e instrumentos}

La muestra fue intencional y se definió por criterios de variación máxima, como lugar de origen, año que cursan, género, ocupación y desempeño escolar. La integraron diez estudiantes, de los cuales cinco eran hombres y cinco, mujeres, con un rango de edad de los quince a los diecinueve años. Al momento del estudio, cuatro cursaban el tercer año, cuatro, el segundo y dos, el primero. Los estudiantes fueron elegidos desde la lógica de "haber vivido la experiencia de llegar al bachillerato"; esto, porque la fenomenología se interesa por la forma en la que las personas experimentan (viven) el mundo antes de abstraerlo, conceptualizarlo o teorizarlo (Van Manen, 2014).

Aplicamos dos instrumentos para la recolección de datos: la entrevista fenomenológica en profundidad y la observación de cerca (centrada en la experiencia vivida). Acordes con Van Manen (2014), en la entrevista solicitamos a los estudiantes: describir la experiencia de llegar al bachillerato tal como la vivieron y evitar hablar de causas, generalizaciones o explicaciones abstractas; referir la experiencia desde adentro (cómo se sentían, cuál era su estado de ánimo, qué emociones tenían); precisar momentos específicos al llegar al bachillerato (cómo estaban formados, cómo eligieron el lugar para sentarse, cómo fue el primer encuentro con los compañeros y maestros, etcétera); y evitar adornar sus respuestas con frases o palabras rebuscadas.

A través de la observación de cerca, nos enfocamos en observar las experiencias vividas de llegar al bachillerato. El interés principal se centró en la pregunta ¿cómo viven los estudiantes el primer contacto con la escuela? A partir de este ejercicio, describimos de forma narrativa cómo los estudiantes viven el hecho de llegar al bachillerato. Tanto las entrevistas como la observación nos permitieron hacer un ejercicio de triangulación de instrumentos y dar confiabilidad a los datos obtenidos.

Nos apegamos a los criterios de validación fenomenológica que Van Manen (2014) propone con base en las siguientes preguntas: ¿el estudio es guiado por una pregunta fenomenológica? ¿El análisis es realizado a partir de relatos o narrativas experienciales? ¿El estudio está basado primordialmente en la literatura fenomenológica? Así pues, el eje de la investigación fue una pregunta fenomenológica que nos aseguró la obtención de descripciones de la experiencia de llegar al bachillerato tal como es vivida (no conceptualizada) a través de los instrumentos elegidos y con base en la fenomenología hermenéutica de Martin Heidegger y Max van Manen.

\section{Momentos de la investigación}

Van Manen $(2003,2014)$, formado en la tradición de Dilthey y en la tradición fenomenológica, propone una estructura elemental que toda investigación de esta naturaleza debe tener: 
- Centrarse en la naturaleza de la experiencia vivida.

-Investigar la experiencia tal como la vivimos.

- Reflexionar fenomenológica-hermenéuticamente.

-Escribir fenomenológica-hermenéuticamente.

- Mantener una relación firme y orientada.

-Equilibrar el contexto de investigación considerando las partes y el todo.

Respecto al primer punto, "centrarse en la naturaleza de la experiencia vivida", delimitamos el objeto de estudio y nos enfocamos en la forma en la que los estudiantes viven el hecho de incorporarse al bachillerato. No debe confundirse con las percepciones 0 las creencias que los estudiantes tienen sobre este hecho, ya que el interés principal es regresar a la experiencia tal como se vive. En este momento también se formuló la pregunta fenomenológica: ¿cómo viven los estudiantes de BGE la experiencia de incorporarse al bachillerato? Una actividad más fue explicar las presuposiciones y los conocimientos previos sobre el fenómeno de estudio, movimiento conocido como epojé.

El siguiente punto, "Investigar la experiencia tal como la vivimos", nos permitió acercarnos al hecho de llegar al bachillerato a través de los instrumentos de recolección de datos. Aplicamos diez entrevistas fenomenológicas en profundidad a igual número de estudiantes y observación de cerca (Van Manen, 2003). A través de las entrevistas, recuperamos la forma en la que los estudiantes vivieron la incorporación al bachillerato y la observación nos ayudó a ver de primera mano la manera en la que los estudiantes "viven este hecho".

Respecto a "la reflexión fenomenológica hermenéutica", analizamos el modo en el que los estudiantes viven el llegar al bachillerato, lo cual nos permitió aplicar la actitud fenomenológica (Finlay, 2014), no dar nada por hecho y emplear la reducción fenomenológica entendida como el volver al fenómeno estudiado tal como se muestra (Heinonen, 2015; Van Manen, 2014). Las entrevistas audiograbadas y los datos obtenidos de la observación se transcribieron digitalmente, y fueron codificados y sometidos a un análisis temático.

Para Van Manen (2003), la noción de tema proporciona orden y control y representa un medio para "ver un significado". En el mismo proceso de análisis y reflexión fenomenológica recurrimos a los existenciales: el tiempo vivido, el espacio vivido, el cuerpo vivido, el otro vivido y las cosas vividas (Van Manen, 2014). Este proceso reveló que los estudiantes de bachillerato de nuevo ingreso enfrentan diversas pruebas de carácter afectivo, curricular y administrativo que se cristalizan en los temas: vivir a la expectativa, falta de conexión, ganarse un lugar, entenderle al profesor y quiebre experiencial, los cuales desarrollamos en la sección de resultados.

La escritura es una parte fundamental de la investigación fenomenológica. Para Van Manen $(2006,2014)$, el propósito principal de toda investigación fenomenológica es la creación de un texto que nos ayude a tener contacto con determinada experiencia vivida. El mismo autor sostiene que la escritura es parte de la reflexión fenomenológica, pues lo escrito ayuda a (re)pensar sobre algún fenómeno de estudio. 
En lo referente a "mantener una relación firme y orientada", en nuestro trabajo existe un interés genuino en obtener un mejor conocimiento pedagógico de la experiencia de incorporación al bachillerato por parte de los jóvenes de BGE. Finalmente, el momento "equilibrar el contexto de investigación" corresponde al cuidado ético del estudio. Cabe mencionar que contamos con el consentimiento informado por parte de alumnos y tutores, y en el tratamiento de los datos asignamos pseudónimos a los estudiantes para salvaguardar su identidad.

\section{RESULTADOS. LA EXPERIENCIA VIVIDA DE LLEGAR AL BACHILLERATO}

En las próximas líneas detallamos los momentos que tienen un significado especial en la vida de los estudiantes que recientemente se han integrado al bachillerato. Los resultados se presentan de modo narrativo desde una perspectiva temática y existencial. Es importante recordar que Van Manen $(2003,2014)$ considera la escritura como una parte fundamental de la investigación fenomenológica, porque esta permite tener contacto directo con determinada experiencia vivida. De acuerdo con este autor, investigar es escribir, pues la investigación no puede ser separada de la práctica de la escritura, ya que facilita la reflexión fenomenológica.

La fenomenología hermenéutica se distingue de otras formas de investigación cualitativa porque sus métodos "nos previenen de los efectos y suposiciones inducidos por la teoría, por la ciencia, por los conceptos, por los valores, por los discursos polémicos y por los prejuicios del sentido común que damos por supuesto en la vida diaria" (Van Manen, 2014, p. 65). Hay que recordar que la fenomenología se interesa por el mundo prerreflexivo (tal como es vivido): "La fenomenología no ofrece la posibilidad de una teoría efectiva con la que podamos explicar y controlar el mundo; más bien, nos ofrece la posibilidad de obtener revelaciones plausibles que nos ponen en contacto directo con el mundo" (Van Manen, 2014, p. 66). Desde esta lógica presentamos los resultados; cabe aclarar que la letra "E" identifica al entrevistador y la "A", al estudiante.

\section{Vivir a la expectativa}

Llegar al bachillerato es vivir a la expectativa. Cuando se llega a un lugar, se tiene cierta carga de expectativas sobre lo que se espera encontrar. La llegada a un sitio nuevo se asemeja a la experiencia del extranjero. El extranjero llega a un lugar que le es ajeno, que no conoce y le genera ciertas expectativas y emociones por conocer un nuevo lugar, pero, al mismo tiempo, le origina una pesada incertidumbre por no saber con exactitud con qué o con quién se va a encontrar.

De forma análoga al extranjero, los estudiantes de bachillerato, antes de poner un pie en el plantel, construyen sus propias expectativas, que se cristalizan en las interrogantes: ¿cómo serán los maestros? ¿Cómo serán los compañeros? ¿Cómo serán las clases? Estas preguntas desatan un sentimiento de inseguridad y falta de certeza: 
E: ¿Cómo te sentiste tú cuando te dieron esta noticia?

A: Pues a la vez contenta, y a la vez como que no. Y ya me sentía como nerviosa cuando ya iba yo a entrar porque, decía yo, en una escuela vas a comenzar el primer día y no sabes qué maestros te toquen, ¿cómo son los maestros? ¿Tus compañeros? (Rebeca, tercer año).

Algunos estudiantes abrevan en la experiencia de sus hermanos mayores que ya cursaron el bachillerato en el mismo plantel. Aun así, los estudiantes viven el ingreso a la expectativa, pues descubren por sí mismos cómo es estudiar este nivel:

E: ¿Y qué te imaginabas de este bachillerato?

A: Me daba miedo entrar porque dije no, yo no la voy a armar acá. Y dice mi hermano, ¡no! está fácil, solamente que pongas atención. Y yo le dije no, es que siento que está difícil, en matemáticas no le entiendo muy bien. Y ya me dijo, ¡no! es fácil, solamente ponle atención a la maestra, cuando no entiendas algo le preguntas. Me daba miedo y él me dijo [...] no te va a pasar nada. Y ¡este! y ya fue cuando el primer día cuando entré fue muy diferente porque yo me lo imaginaba a que iban a ser muy estrictos, bien enojones y no sé. Sentía que si me equivocaba en algo me iban a llamar mucho la atención. ¡Ajá!, muy enojones. Y cuando entré, pues fue muy diferente (Viviana, segundo año).

Entre las expectativas que más aparecen entre los estudiantes es la pregunta por el Dasein (la forma de ser) del profesor. Existe una preocupación por la manera en la que los profesores van a reaccionar hacia las actitudes de los jóvenes:

E: ¿Cómo fueron los primeros días en el bachillerato?

A: Pues, el primer día estaba yo nerviosa porque apenas iba yo a conocer a todos los maestros. Y pues, como ya conocía yo a todos los compañeros de ahí del salón.

E: ¿Ya conocías a todos?

A: Sí, ya conocía a todos porque estudiamos en la misma técnica (secundaria).

E: ¿Tú ya tenías amigos entonces?

A: ¡Ajá!, y después nos dijeron qué materias nos iban a dar y estuvo divertido la verdad cuando se empezaron a presentar los profesores porque nos hablaron de una buena manera, nos explicaron cómo iban a dar sus clases y así, y cómo iban a evaluar todo.

E: ¿Y entendías?

A: Pues más o menos. Al principio, al primer maestro no le entendí muy bien, ya después vino uno más bromista (Xóchitl, segundo año).

\section{El bachillerato vivido como falta de conexión}

La llegada al bachillerato está marcada por un sentimiento de no pertenencia, de falta de conexión. En cualquier estructura, un elemento que no está conectado carece de contacto con la estructura; por lo tanto, está aislado de ella. Esto puede interpretarse como un elemento que no pertenece, un elemento que es extraño:

Cuando primero recién entré pues se siente uno raro, como es escuela nueva, se siente uno raro. No se siente uno conforme ¿cómo? ¿Cómo le diría? ¡Qué una conexión! ¡Qué todavía no te puedes conectar a la escuela! (Ramón, segundo año). 
La llegada al bachillerato es vivida por los jóvenes con una fuerte carga de falta de conexión, lo que Ganeson y Ehrich (2009) tipifican como falta de pertenencia. Dentro de este abrumador sentimiento de no pertenecer a la escuela se busca un puerto seguro. El joven acude al Ser-con otros (Heidegger, 1997). El sentimiento de falta de conexión se mitiga con el establecimiento de pequeñas redes, se busca a los rostros conocidos, a los ex compañeros, a los amigos:

E: ¿Recuerdas el primer día? ¿Cómo fue?

A: ¡Bueno! Pues el primer día llegué y empezaron a decir los nombres de los que iban. Y ya dijeron salón "B" se van a tal salón, y ya dijeron "N" Martínez ¡no, pues ese soy yo! y ya que me meto al salón. ¡Ah! y hasta atrás, hasta atrás porque muchas veces el relajo lo ponen que adelante o hasta atrás también. Y yo dije pues yo me voy "pa" atrás. Y me fui con Bryan que era el único con el que entramos ahí en primero B, y ahí estábamos sentados. Ya después, pues llegaron a presentarse los profes, qué clase iban a dar, cómo nos iban a evaluar (Elías, segundo año).

En la búsqueda de los conocidos, los rostros de los demás aparecen como las miradas que hurgan en el ser de los estudiantes. El joven, por su parte, tipifica a los compañeros imaginando si es posible encajar con ellos a partir de la imagen que estos proyectan:

\section{E: ¿Cómo te sentías tú?}

A: Rara, porque yo siempre cuando llego a un salón los primeros días es de sentirme como bicho raro, como no los conozco ¿o qué tal no les caigo? 0 ¿qué tal no soy de su cuadrante de ellos? La verdad yo los oía y jay!, son como que de más varo que yo, son de más presumiditos o algo así. Eso fue los primeros días (Graciela, tercer año).

El sentimiento de extrañeza se elimina a partir del encuentro e intercambio con los demás. Esta acción dota a los estudiantes de un conocimiento que ayuda a delimitar límites de comportamiento, se sabe con quién se puede tener una relación más llevadera y con quién hay que ser precavido al actuar. Esto se da a partir de un ejercicio de aprehensión del Dasein de los estudiantes, de la comprensión de la forma en la que los compañeros están-en-el-mundo:

Ahorita como ya conozco a todos me siento seguro, como seguro porque los conozco. Ellos me hablan, ya agarramos amistad con ellos en el salón. Entonces ¡este! si yo quisiera hablar con alguien simplemente yo tengo que acercarme y hacerles plática. Ya no es de me da medio hablarles, ahora ya los conozco, ya sé cómo son. Ahora ya sé de quién cuidarme y de quién no, ahora sí (Pablo, primer año).

De igual modo, se valora el hecho del reconocimiento. Ser reconocido o recibir reconocimiento por los demás ayuda a una rápida adaptación a los nuevos contextos (DeRobertis, 2017). El reconocimiento se vive como un proceso de aceptación, ser aceptado y reconocido por los demás, "recibir reconocimiento literalmente significa ser conocido. Alguien que me reconoce aprecia mi existencia, mi verdadero ser" (Van Manen, 2016, p. 143):

Yo no conocía a nadie de con todos [sic] los que me llevo ahorita, los vine conociendo en el transcurso de... Y pues ya el segundo día, el primer día creo que nos dejaron tarea, el segundo día pues yo la entregué, yo cumplí. Y pues todos mis compañeros me veían como lista o como si fuera la gran cosa (Diana, primer año). 


\section{Ganarse un lugar}

El espacio vivido es distinto al espacio físico o geográfico, y hace referencia al espacio sentido, al sentimiento que los espacios despiertan en nosotros (Van Manen, 2014). No se siente del mismo modo estar en casa que estar en una casa ajena. En esta línea, el salón de clases se siente como una distribución no dicha y que se toma de manera tácita. Los espacios del salón de clase tienen una distribución sentida (según como la viven los estudiantes) en la que se debe ganar el espacio:

E: Entonces ahora sí, cuéntanos ¿cómo fueron los primeros días aquí?

A: Los primeros días, pues el primer día yo llegué y pues yo no conocía a nadie, nada más a mi primo. Me senté, a mí me gustan siempre los lugares de enfrente pero dije no sé, vaya a venir alguien más listo que yo o bueno que tenga más potencial que yo y dije mejor me siento atrás. Me senté atrás con mi primo. Yo me quería sentar adelante pero dije no, mejor me voy para atrás con mi primo, a él siempre le ha gustado el lugar de hasta atrás. Estuve con él el primer día, creo que nos presentamos, jah!, nos dijeron a dónde nos iba a tocar y todo eso (Diana, primer año).

Al llegar al salón por primera vez, los estudiantes actúan con cautela debido al desconocimiento de los demás y al deseo de no querer usurpar un sitio que no sienten propio. El lugar donde los estudiantes se sientan en el salón de clase es visto como un espacio que debe ganarse.

\section{Entenderle al profesor}

El sentimiento que despierta el profesor en el alumno es significativo en los primeros días en el bachillerato. ¿Cómo serán los maestros? Es una pregunta que aparece con mucha frecuencia en los jóvenes. Esta falta de conocimiento de la forma de ser del profesor les provoca sentimientos de inseguridad:

E: ¿Cómo te sentías ese primer día?

A: Como con miedo, estás conociendo a los profes que ¿quién sabe cómo serán? ¿Cuál será enojón y eso? (Elías, segundo año).

Comprender la forma de ser del profesor es un aspecto importante. Los estudiantes entran en un proceso de aprehensión del Dasein (Heidegger, 1997) de los profesores, y entienden que estos están en el mundo de una determinada manera:

En primer año porque tuvimos un error. Trabajamos, pero, o sea que no le agarrábamos al profe como es su forma de ser, no sabíamos cómo era él. ¡Bueno!, cómo era con las personas porque a él le gusta también ser bien sociable con las personas, llevarse con todo mundo. Y nosotros pues también no sabíamos que así era, pero ya después lo conocimos y ya otro maestro, ya pues todos los maestros ya sabemos cómo son. A veces, más cuando entraba "N" nos daba miedo, pues ya viene el maestro que ¿qué vamos a hacer? A veces nos regaña y está bien para que aprenda uno. 0 el "N" a veces nos regaña, de que tiene su voz "chicos tienen que hacer esto o se me van para afuera" [emulando la voz de un profesor]. Y pues mejor lo hacíamos como dicen los señores "a trompa y talega" (Esteban, tercer año).

La aprehensión del Dasein de los profesores por parte de los estudiantes se da dentro de la convivencia del día a día. A partir de esta aprehensión, los estudiantes definen formas de actuación: 
E: ¿Cómo te imaginabas tú que sería estudiar el bachillerato?

A: Pues yo pensé que iba a ser muy difícil.

E; ¿Por qué?

A: Porque en sí iba a ser más trabajo, más tareas que iban a dejar. ¡Ujum!

E: ¿Y qué te parece entonces? ¿Te parece muy difícil?

A: Pues ahorita no, me parece normal, se va uno adaptando a las exigencias de cada maestro (Ricardo, tercer año).

\section{Quiebre experiencial}

La experiencia vivida en el bachillerato dista de la experimentada en la secundaria. En este sentido, se puede hablar de un quiebre experiencial de carácter vivencial entre la secundaria y el bachillerato. Los jóvenes bachilleres encuentran una nueva lógica de organización de la escuela, que debe ser comprendida y sometida a un proceso de apropiación. En los primeros días, los jóvenes se dan cuenta de que existen diferencias entre estudiar la secundaria y estudiar el bachillerato, las cuales radican en lo administrativo y en lo académico; por ejemplo, encuentran una mayor carga de trabajo:

E: ¿Costó trabajo adaptarse?

A: No, es lo mismo. A lo mejor un poco más de tarea aquí que en la secu. A veces cada profe te deja una tarea y allá en la secundaria dos o tres tareas, como era el mismo profesor. Pero no, de ahí en fuera, como me siento capaz de aprender, yo decía, pues en donde sea (Elías, segundo año).

Otra diferencia significativa es la forma de evaluación; los estudiantes encuentran una nueva manera de ser evaluado, la cual no queda del todo clara al inicio del bachillerato:

E: ¿Cómo fue la primera semana de clase?

A: La primera semana pues que sabes qué, te toca tal o cual maestro. Y sin entender las cosas a veces llega uno. Sabes que la puntuación [alude a la ponderación de la evaluación], lo que se va a evaluar es esto, un $30 \%$ la actitud, tienes que completar 100 . Y a veces yo como que entendía y a veces como que no y preguntaba. Y llega otro maestro y yo me llamo así, pero ¿cómo se llama ese maestro?, y ahí pensando se llama así y se llama así, se olvidaba. Pero ya después empezamos a agarrar la onda de las materias. El primer parcial sacamos muy buenas calificaciones, igual el segundo, ya el tercero poco bajamos pero pasamos todavía la materia. ¡Bueno!, no me recuerdo con cuánto y así se fue, así se fue hasta pasar, ya ahorita venimos en sexto semestre y vamos bien (Esteban, tercer año).

A diferencia de la secundaria, los jóvenes viven el bachillerato como una etapa en la que se es libre y se aprende a ser responsable. Los estudiantes identifican que en la secundaria están concentrados "en hacer cosas más de niños"; hay una mayor vigilancia por entrar a clase por parte de los prefectos. El BGE carece de una figura similar; los estudiantes asumen que entrar a clase depende más de ellos mismos. Esto representa un punto de partida significativo, pues de ahora en adelante los pasos que vayan dando dependerán cada día más de ellos: 
E: ¿Qué diferencia encuentras entonces entre la secundaria y el bachi?

A: En que allá te encontraban afuera y te metían a fuerza. "Ora" sí que te obligaban a estar adentro. Y acá no, porque si te sales solo te llaman una vez, si no es tu problema, ya perdiste apuntes (alude a las notas tomadas en clase), ya perdiste firmas y allá no. La prefecta se preocupaba demasiado por nosotros, te salías y te metía, donde sea que estuvieras, aunque estuvieras en el baño, te iba a buscar y te metía a fuerza y aquí no. Pues ya estás afuera y cierran la puerta y ya no puedes entrar a veces. Es lo que sentí yo, allá a veces nos cuidaban demasiado y acá eres responsable de las cosas que estás haciendo (Viviana, segundo año).

En general, se vive un cambio en el trato que los jóvenes reciben por parte de los profesores. Como ha mencionado la anterior estudiante, no se trata de que los maestros anden detrás de ellos para obligarlos a entrar a clase como en la secundaria. Este hecho se vive por los jóvenes como un proceso que obliga a cambiar:

E: ¿Y cómo fueron los primeros días en este bachillerato? Primer año, primeros días.

A: ¡Este!, la primera semana fue difícil porque o sea que era un cambio que iba de, ¡este!, de la secundaria al bachiller. Pues un cambio más fuerte porque en sí, la forma de que nos tratan en la secundaria y la que nos tratan aquí era diferente. 0 sea, tenía uno que cambiar (Ricardo, tercer año).

\section{REFLEXIONES FINALES}

En este estudio nos posicionamos desde una mirada ontológica que nos permitió develar las vivencias que le acontecen al estudiante al momento de incorporarse al bachillerato. La llegada al bachillerato se revela como una etapa significativa dentro de la experiencia escolar de los jóvenes, quienes, al incorporarse, se enfrentan a pruebas de carácter afectivo y administrativo debido al descubrimiento de un nuevo mundo representado por el bachillerato.

La llegada al bachillerato enfrenta a los estudiantes a una serie de desafíos. Las preocupaciones de los jóvenes de recién ingreso son de carácter ontológico: no sentirse parte del plantel, la preocupación por ganarse un espacio en la escuela, el desconocimiento de la forma de ser del profesor, y el quiebre experimentado entre la secundaria y el bachillerato. El joven estudiante se ve obligado a comprender una nueva lógica, a entender las nuevas condiciones que plantea el bachillerato, a aprehender el Dasein del profesor y el de los compañeros.

La llegada al bachillerato implica ciertos retos para la educación de la vida cotidiana. En primer lugar, el bachillerato se ve obligado a construir espacios de bienvenida, crear ambientes que fomenten "la conexión" del estudiante de nuevo ingreso. En segundo, obliga al profesor a manifestar de forma clara y concisa su forma de estar-en-el-mundo, su forma de ser y de actuar. En tercero, se requiere un programa de inducción que ayude a la aprehensión de los detalles de carácter académicoadministrativo (una mayor carga de trabajo y una nueva forma de ser evaluado) que implica el bachillerato.

Finalmente, es importante mejorar las relaciones e interacciones que se establecen en el espacio escolar. De acuerdo con Martuccelli (2007), podemos concluir que las relaciones con los demás son el soporte existencial que dota a los estudiantes de 
cierta seguridad y ayuda a disminuir el sentido de “desconexión”. De igual modo, la experiencia del reconocimiento es parte fundamental del proceso de "conexión". Es esencial que los profesores fomenten actividades en las que se reconozca la existencia de estos jóvenes que se integran a un espacio que le es ajeno y no les pertenece.

\section{REFERENCIAS BIBLIOGRÁFICAS}

Coulon, A. (1997). Le métier d'étudiant. L'entrée dans la vie universitaire. París: Presses Universitaires.

Cueto, S., Guerrero, G., Sugimaru, C. \& Zevallos, A. M. (2010). Sense of belonging and transition to high schools in Peru. International Journal of Educational Development, vol. 30, núm. 3, pp. 277-287. http://doi.org/10.1016/j.ijedudev.2009.02.002

DeRobertis, E. M. (2017). The phenomenology of learning and becoming: enthusiasm, creativity, and self-development. Nueva York: Palgrave Macmillan US.

Finlay, L. (2014). Engaging phenomenological analysis. Qualitative Research in Psychology, núm. 11, pp. 121-141. http://doi.org/10.1080/14780887. 2013.807899

Finlay, L. (2009). Debating phenomenological research methods. Phenomenology \& Practice, vol. 3, núm. 1, pp. 6-25. http://doi.org/10.1007/978-94-6091-834-6_2

Friesen, N., Henriksson, C. \& Saevi, T. (eds.) (2012). Hermeneutic phenomenology in education. Method and practice. Rotterdam: Sense Publishers.

Ganeson, K. \& Ehrich, L. C. (2009). Transition into high school: A phenomenological study. En G. Dall'Alba (ed.). Exploring education through phenomenology. Diverse approaches (pp. 66-84). West Sussex: Wiley-Blackwell.

Guzmán, C. (2011). Avances y retos en el conocimiento sobre los estudiantes mexicanos de educación superior en la primera década del siglo XXI. Perfiles educativos, vol. 33, pp. 91-101.

Guzmán, C. y Saucedo, C. L. (2007). La voz de los estudiantes: experiencias en torno a la escuela. Mexico, DF: Ediciones Pomares.

Hanewald, R. (2013). Transition between primary and secondary school: Why it is important and how it can be supported. Australian Journal of Teacher Education, vol. 38, núm. 1, pp. 61-74. http://doi.org/10.14221/ajte.2013v38n1.7

Heidegger, M. (1997). Ser y tiempo. Santiago: Editorial Universitaria.

Heinonen, K. (2015). van Manen's method and reduction in a phenomenological hermeneutic study. Nurse Researcher, vol. 22, núm. 4, pp. 35-41. http://doi. org/10.7748/nr.22.4.35.e1326

Hess, F. M. (2016). College readiness for all? Educational leadership, vol. 73, núm. 6, pp. 36-41.

Hodge, S. (2015). Martin Heidegger: Challenge to education. Nueva York: Springer.

INEE. (2017). La educación obligatoria en México. Informe 2017. México.

Larrosa, J. (2010). Herido de realidad y en busca de realidad. Notas sobre los lenguajes de la experiencia. En J. Contreras y N. Pérez de Lara (eds.). Investigar la experiencia educativa (pp. 87-116). Madrid: Morata.

Larrosa, J. (2006). Algunas notas sobre la experiencia y sus lenguajes. Estudios Filosóficos, vol. 55, núm. 160, pp. 467-480. 
Laverty, S. M. (2003). Hermeneutic phenomenology and phenomenology: A comparison of historical and methodological considerations. International Journal of Qualitative Methods, vol. 2, núm. 3, pp. 21-35. http://doi.org/10.1016/ S0742-051X(00)00023-8

Martuccelli, D. (2007). Cambio de rumbo. La sociedad a escala del individuo. Santiago de Chile: Editorial LOM.

OECD (2013). Mejorar la educación en México, una perspectiva estatal desde Puebla. Secretaría de Educación Pública del Estado de Puebla. http://doi. org/10.1787/9789264205178-es

Rice, J. K. (2001). Explaining the negative impact of the transition from middle to high school on student performance in mathematics and science. Educational Administration Quarterly, vol. 37, núm. 3, pp. 372-400. http://doi. org/10.1177/00131610121969352

Saucedo, C., Guzmán, C., Sandoval, E. y Galaz, J. (2013). Estudiantes, maestros y académicos en la investigación educativa: tendencias, aportes y debates, 20022011. México, DF: ANUIES.

SEP (2016). Principales cifras del Sistema Educativo Nacional 2014-2015. México, DF.

Tapia, G. (2015). Estudiantes en la transición rural-urbana del Bajío: los significados del bachillerato y del trabajo. Centro de Investigación y de Estudios Avanzados del Instituto Politécnico Nacional.

Van Manen, M. (2016). Pedagogical tact. Knowing what to do when you don't know what to do. Nueva York: Routledge.

Van Manen, M. (2014). Phenomenology of practice: Meaning-giving methods in phenomenological research and writing. Walnut Creek: Left Coast Press.

Van Manen, M. (2006). Writing qualitatively, or the demands of writing. Qualitative Health Research, vol. 16, núm. 5, pp. 713-722. http://doi. org/10.1177/1049732306286911

Van Manen, M. (2003). Investigación educativa y experiencia vivida. Barcelona: Idea Books.

Weiss, E. (2012a). Jóvenes y bachillerato. México: ANUIES.

Weiss, E. (2012b). Los estudiantes como jóvenes. El proceso de subjetivación. Perfiles Educativos, vol. XXXIV, núm. 135, pp. 134-148.

Weller, S. (2007). "Sticking with your mates?" Children's friendship trajectories during the transition from primary to secondary school. Children and Society, vol. 21, núm. 5, pp. 339-351. http://doi.org/10.1111/j.10990860.2006.00056.x

West, P., Sweetingm, H. \& Young, R. (2010). Transition matters: Pupils' experiences of the primary-secondary school transition in the West of Scotland and consequences for well-being and attainment. Research Papers in Education, vol. 25. http://doi.org/10.1080/02671520802308677 